\title{
Small Intestinal Obstruction, CTCAE
}

National Cancer Institute

\section{Source}

National Cancer Institute. Small Intestinal Obstruction, CT CAE. NCI Thesaurus. Code C143843.

A disorder characterized by blockage of the normal flow of the intestinal contents of the small intestine. 